\title{
A study on prospective associations between adiposity and 7-year changes in movement behaviors among older women based on compositional data analysis
}

Jana Pelclová ${ }^{*}$, Nikola Štefelová ${ }^{2}$, Timothy Olds ${ }^{3}$, Dorothea Dumuid ${ }^{3}$, Karel Hron ${ }^{2}$, Sebastien Chastin ${ }^{4}$ and Željko Pedišić ${ }^{5}$

\begin{abstract}
Introduction: It is unclear whether adiposity leads to changes in movement behaviors, and there is a lack of compositional analyses of longitudinal data which focus on these associations. Using a compositional approach, this study aimed to examine the associations between baseline adiposity and 7-year changes in physical activity (PA) and sedentary behavior (SB) among elderly women. We also explored the longitudinal associations between change in adiposity and change in movement-behavior composition.

Methods: This longitudinal study included 176 older women (mean baseline age 62.8 (4.1) years) from Central Europe. Movement behavior was assessed by accelerometers and adiposity was measured by bioelectrical impedance analysis at baseline and follow-up. A set of multivariate least-squares regression analyses was used to examine the associations of baseline adiposity and longitudinal changes in adiposity as explanatory variables with longitudinal changes in a 3-part movement-behavior composition consisting of SB, light PA (LPA) and moderate-tovigorous PA (MVPA) as outcome variables.

Results: No significant associations were found between baseline adiposity and longitudinal changes in the movement-behavior composition ( $p>0.05$ ). We found significant associations of changes in body mass index (BMI) and fat mass percentage (FM\%) with changes in the movement-behavior composition. An increase in BMI was associated with an increase of SB at the expense of LPA and MVPA $(\beta=0.042, p=0.009)$ and with a decrease of MVPA in favor of SB and LPA ( $\beta=-0.059, p=0.037)$. An increase in FM\% was significantly associated only with an increase of SB at the expense of LPA and MVPA $(\beta=0.019, p=0.031)$.

\footnotetext{
* Correspondence: jana.pelclova@upol.cz

${ }^{1}$ Faculty of Physical Culture, Palacký University Olomouc, Institute of Active Lifestyle, Tř. Míru 117, 77111 Olomouc, Czech Republic

Full list of author information is available at the end of the article
}

C The Author(s). 2021 Open Access This article is licensed under a Creative Commons Attribution 4.0 International License, which permits use, sharing, adaptation, distribution and reproduction in any medium or format, as long as you give appropriate credit to the original author(s) and the source, provide a link to the Creative Commons licence, and indicate if changes were made. The images or other third party material in this article are included in the article's Creative Commons licence, unless indicated otherwise in a credit line to the material. If material is not included in the article's Creative Commons licence and your intended use is not permitted by statutory regulation or exceeds the permitted use, you will need to obtain permission directly from the copyright holder. To view a copy of this licence, visit http://creativecommons.org/licenses/by/4.0/. The Creative Commons Public Domain Dedication waiver (http://creativecommons.org/publicdomain/zero/1.0/) applies to the data made available in this article, unless otherwise stated in a credit line to the data. 


\begin{abstract}
(Continued from previous page)
Conclusions: This study did not support the assumption that baseline adiposity is associated with longitudinal changes in movement behaviors among elderly women, but we found evidence for change-to-change associations, suggesting that a 7-year increase in adiposity is associated with a concurrent increase of SB at the expense of LPA and MVPA and with a concurrent decrease of MVPA in favor of LPA and SB. Public health interventions are needed to simultaneously prevent weight gain and promote physically active lifestyle among elderly women.
\end{abstract}

Keywords: Compositional data analysis, Time-use epidemiology, Fatness, Obesity, Sitting, Exercise

\section{Introduction}

Previous studies have found that physical activity (PA) and sedentary behavior (SB) are associated with adiposity [1-4]. In prospective cohort studies, low PA and high $\mathrm{SB}$ at baseline have usually been associated with higher subsequent adiposity [5, 6]. However, some studies provided evidence suggesting that adiposity may lead to subsequent changes in movement behaviors [7]; specifically, to reduced PA [8] and increased SB [9]. It seems, therefore, that the association between adiposity and movement behaviors may be bidirectional.

Higher PA may plausibly lead to lower adiposity through higher energy expenditure, but conversely higher adiposity may lead to reductions in PA through increased discomfort and lower fitness. The same applies mutatis mutandis to SB.

Importantly, PA and SB are co-dependent. Since there are only $24 \mathrm{~h}$ in a day, any change to the amount of time we spend in one of the two behaviors must be compensated by an equal and opposite change in the other behavior and sleep collectively $[10,11]$. It therefore makes more sense to talk about activity compositions rather than individual movement behaviors, and to ask whether composition of activity is related to adiposity. For this purpose, it is recommended to use compositional data analysis [1014]. Some studies have found significant cross-sectional relationships, with compositions with high levels of moderate to vigorous PA (MVPA) being favorably associated with adiposity [10]. This relationship has also been explored in several longitudinal studies $[15,16]$. However, there is a lack of compositional analyses of longitudinal data which focus on the association between baseline adiposity and subsequent changes in movement behaviors.

Using a compositional approach, this study, therefore, aimed to examine the prospective associations between baseline adiposity and 7-year changes in PA and SB among elderly women. We also explored the longitudinal associations between change in adiposity and change in movement-behavior composition.

\section{Methods}

\section{Design and participants}

This 7-year longitudinal study was conducted among elderly women from three Central European countries, namely, the Czech Republic, Poland and the Slovak Republic (Fig. 1). The baseline data collection was conducted between 2009 and 2012 and included 409 women aged $60+$, who were able to walk without any prosthetic aids and were not living in a residential care. These women were recruited amongst attendees of University of Third Age programs. The follow-up assessments, previously scheduled by phone call, were arranged individually with each participant between 2016 and 2019. Out of the 409 baseline participants, $17.6 \%$ were not willing to participate in some part or in all parts of the follow-up assessment, $6.8 \%$ could not be contacted due to invalid phone number or address, $15.9 \%$ were unable to repeat the assessment due to short- or long-term serious health problems, and 10.3\% died. All participants were informed that their participation was voluntary and that they could withdraw from the study at any time. They provided their written consent before participating in baseline and follow-up measurements. The study was approved by the Institutional Research Ethics Committee, Faculty of Physical Culture, Palacký University Olomouc. A detailed description of the study can be found elsewhere [17].

\section{Measures \\ Adiposity}

Body Mass Index (BMI) was calculated from standing height measured using the P-375 portable stadiometer to the nearest $0.1 \mathrm{~cm}$ (Trystom, Olomouc, Czech Republic). Body weight was measured to the nearest $0.5 \mathrm{~kg}$ using the InBody 720 device (Biospace Co., Ltd., Seoul, Korea). The same device was also used to assess fat mass percentage (FM\%) through bioelectrical impedance analysis. The device was found to have acceptable validity for assessing FM\% $[18,19]$. The participants were asked to hydrate properly for $24 \mathrm{~h}$, fast for at least $2 \mathrm{~h}$ and avoid any vigorous activity at least $48 \mathrm{~h}$ before the adiposity assessment was conducted. The same protocol was followed for adiposity assessment at baseline and follow-up. For sample description, BMI was categorized as 'normal' weight $(<25 \mathrm{~kg} / \mathrm{m} 2)$, overweight $(25-29.9 \mathrm{~kg} /$ $\left.\mathrm{m}^{2}\right)$ and obesity $\left(\geq 30 \mathrm{~kg} / \mathrm{m}^{2}\right)$ [20], while body fat 


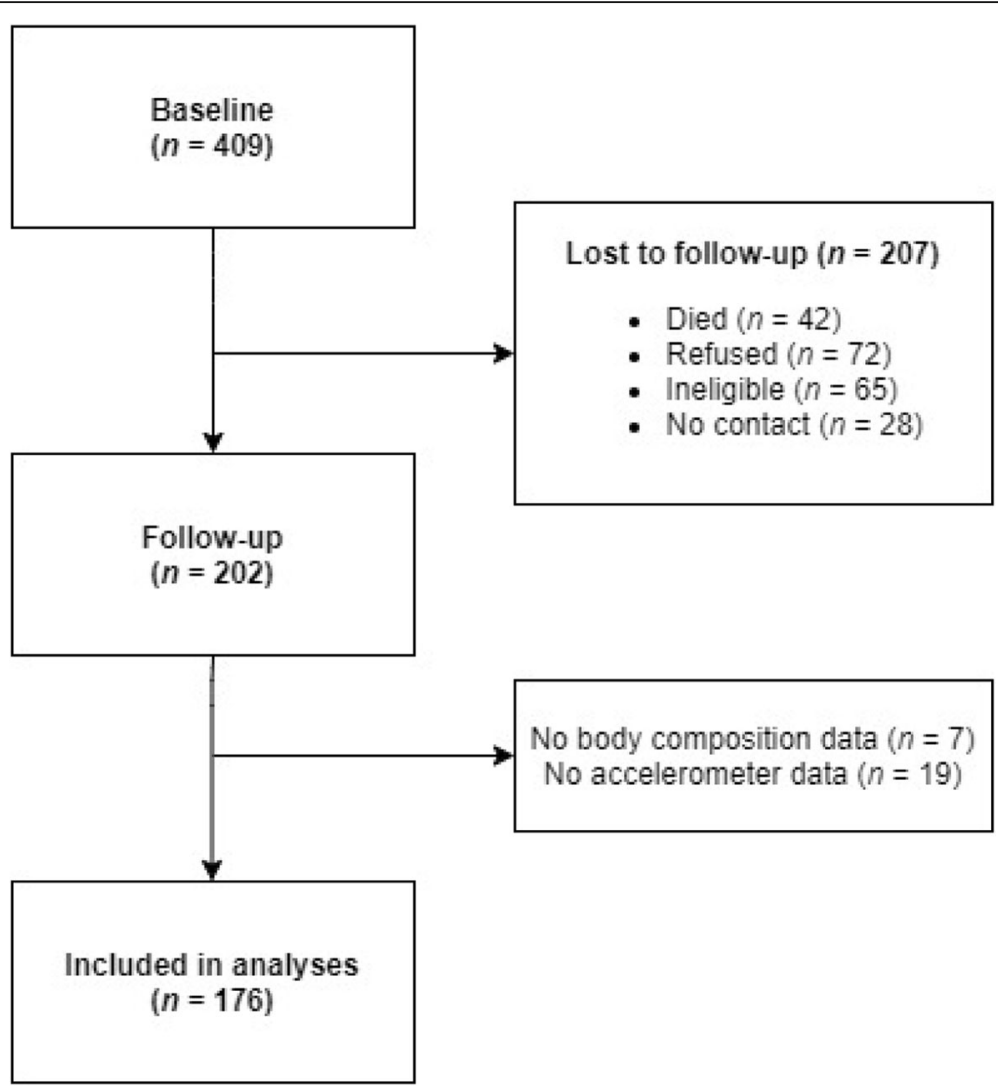

Fig. 1 Flow diagram of participation in longitudinal study

percentage (\%BF) was classified as 'normal' $(<35 \%)$ and obesity ( $\geq 35 \%)[21]$.

\section{Movement behaviors}

To assess the amounts of time spent in PA and SB at baseline and follow-up, the participants were asked to wear an ActiGraph GT1M accelerometer (Manufacturing Technology Inc., Pensacola, FL, USA) on their right hip for at least seven consecutive days. The sampling interval was set at $1 \mathrm{~min}$, and non-wear time was defined as any interval of 60 or more minutes with no activity counts, with allowance for up to 2 min with 0-100 activity counts per minute. In accordance with the study protocol [17], the participants were asked to wear the device during waking hours only, to put it on immediately after waking up and to remove it before falling asleep. They were also instructed to remove the device during water activities (e.g. swimming, bathing, showering). The participants with at least 4 days (including at least three weekdays and one weekend day) with $\geq 10$ wear time hours were included in the data analysis. Using the ActiGraph software, the amount of time spent in SB, light PA (LPA) and moderate-to-vigorous PA (MVPA) was derived from activity counts (ActiGraph, LLC, Pensacola, FL, USA). We used the following cut- points: < $100 \mathrm{cpm}$ for SB [22], $100-1951 \mathrm{cpm}$ for LPA [23] and $\geq 1952$ cpm for MVPA [23].

\section{Other measures}

Education level was self-reported by participants at baseline, and it was dichotomized as "primary/secondary education" and "tertiary degree". Participants also self-reported their place of residence, employment status and marital status at baseline and follow-up. Employment status was categorized as "employed", "unemployed" and "retired". Marital status was dichotomized as "living alone" and "living with a partner". Health status was assessed using open-ended questions on different illness or disability occurrence before baseline and during the 7-year period between baseline and follow-up. The participants provided information about occurrence of cardiovascular disease, musculoskeletal disorders, chronic respiratory diseases, cancer, diabetes, urogenital or endocrine diseases, and osteoporosis before baseline and during the 7-year follow-up period. Health status was dichotomized as "illness/ disability occurrence" and "no illness/disability occurrence". 


\section{Statistical analysis}

Statistical analyses were performed using the R Statistical Software, version 3.4.2 [24] using the compositions [25] package and the IBM Statistical Package for the Social Sciences software, version 23 (SPSS Inc., an IBM Company, Armonk, NY, USA). To examine the prospective association between baseline adiposity and 7year changes in a 3-part movement-behavior composition consisting of SB, LPA and MVPA, we used compositional data analysis (CoDA) [26]. Compositional data analysis acknowledges the relative nature of time-use data by expressing them as a set of log-ratios. The logratios can then be analysed instead of raw absolute values (e.g., minutes of MVPA), using standard statistical models [27]. Movement compositions were mapped into real Euclidean space using specific isometric log-ratio coordinates called pivot coordinates [28].

We conducted a set of multivariate robust compositional regression analyses with changes in movement behaviors (calculated from pivot coordinates of baseline and follow-up movement compositions) as dependent variables and baseline BMI, (baseline FM\% respectively), change in BMI (and change in FM\% respectively) as explanatory variables. The regression models were adjusted for baseline age, country, follow-up duration, baseline wear-time, follow-up wear-time, baseline movementbehavior composition, change in adiposity, education, residence change (dummy variable), baseline employment status, change in employment status (dummy variables representing no change, transition to retirement, and transition from unemployment to employment), baseline health status, change in health status, baseline marital status and follow-up marital status. The necessary adjustments for confounding were determined using a directed acyclic graph (DAG), where the causal assumptions were made based on findings from previous studies among older adults [29]. Three models were run, each with a different permutation of the movement behaviors within the pivot co-ordinates, to allow interpretation of each movement behavior relative to other movement behaviors. Significance level was set at $p<$ 0.05. A comprehensive explanation of the compositional analysis is included in Supplementary file.

\section{Results}

\section{Sample characteristics}

The formation of the final study sample is shown in Fig. 1. Out of 202 women who attended follow-up, 176 had valid data. Of these, 44.9, 35.8 and 19.3\% were from the Czech Republic, Poland and the Slovak Republic, respectively. At baseline, most of the participants were retired (73.3\%) and lived with a partner (73.9\%). During the 7 years between baseline and follow-up, $67.6 \%$ of participants reported occurrence of disability or illness, $52.8 \%$ (out of 36 participants who were employed at baseline) retired and $5 \%$ of participants changed their place of residence. At follow-up, $41.6 \%$ lived alone.

\section{Longitudinal changes in adiposity and movement- behavior composition}

The mean and standard deviation of follow-up duration was 84 (6) months. The mean daily accelerometer weartime was 14.1 (1.2) and 13.6 (1.2) hours/day at baseline and follow-up, respectively. Descriptive statistics for adiposity measures and movement-behavior compositions are presented in Table 1 . There were significant longitudinal changes in BMI and adiposity (Table 1). During the study period, BMI and FM\% increased on average by $1 \mathrm{~kg} / \mathrm{m}^{2}$ and $2.3 \%$, respectively ( $p<0.001$ for both). According to BMI, the prevalence of obesity increased from $19 \%$ at baseline to $24 \%$ at follow-up $(p=0.01)$. According to FM\% the prevalence of obesity increased from $47 \%$ at baseline to $61 \%$ at follow-up $(p=0.01)$. During the 7 years, the average amount of time spent in SB increased by $14 \%$, while the average amounts of time spent in LPA and MVPA decreased by 15 and $17.5 \%$, respectively. The prevalence of women meeting the recommendation of $150 \mathrm{~min} /$ week of MVPA [30-32] decreased from $78.2 \%$ at baseline to $64.3 \%$ at follow-up. Furthermore, the prevalence of women sitting less than $8 \mathrm{~h}$ a day decreased from $70.5 \%$ at baseline to $52.3 \%$ at followup.

\section{Association between adiposity and 7-year changes in movement-behavior composition}

We did not find significant associations of baseline BMI and FM\% with longitudinal changes in movement-behavior composition (Table 2). We found significant associations between changes in adiposity from baseline to follow-up and changes in some parts of the movement-behavior composition from baseline to follow-up (Table 2). Specifically, an increase in BMI was associated with an increase of SB at the expense of LPA and MVPA $(\beta=0.042, p=0.009)$ and with an increase of SB at the expense of MVPA $(\beta=0.057, p=0.021)$. An increase in BMI was also associated with a decrease of MVPA in favor of SB and LPA $(\beta=-0.059, p=0.037)$. An increase in FM\% was significantly associated only with an increase of $\mathrm{SB}$ at the expense of LPA and MVPA $(\beta=0.019, p=0.031)$. We did not find any significant associations between BMI or FM\% change and change in LPA (relative to the remaining movement behaviors).

\section{Discussion}

Our results suggest that among elderly women a longitudinal change in adiposity over 7 years is associated with a concurrent change in movement-behavior composition. We did not find a significant prospective 
Table 1 Sample characteristics at baseline and follow-up

\begin{tabular}{|c|c|c|c|c|c|c|c|}
\hline & \multicolumn{2}{|c|}{ Baseline } & \multicolumn{2}{|c|}{ Follow-up } & \multicolumn{3}{|c|}{ Difference $^{a}$} \\
\hline & Mean & Var & Mean & Var & Mean & Var & $p$ \\
\hline Age (years) & 62.8 & 4.1 & 69.8 & 4.2 & 7.0 & 0.6 & $<0.001$ \\
\hline Height (cm) & 160.8 & 6.5 & 159.7 & 6.7 & -1.0 & 1.4 & $<0.001$ \\
\hline Weight (kg) & 68.3 & 10.3 & 69.7 & 11.2 & 1.4 & 4.8 & $<0.001$ \\
\hline $\mathrm{BMI}\left(\mathrm{kg} / \mathrm{m}^{2}\right)$ & 26.4 & 4.0 & 27.3 & 4.2 & 0.9 & 1.9 & $<0.001$ \\
\hline \multicolumn{8}{|l|}{ Body composition } \\
\hline Fat mass percentage (\%) & 34.6 & 6.3 & 36.8 & 6.6 & 2.2 & 3.8 & $<0.001$ \\
\hline \multicolumn{8}{|c|}{ Movement-behavior composition } \\
\hline SB (\%) & 52.2 & 58.9 & 59.5 & 59.0 & 7.3 & & \\
\hline LPA (\%) & 43.8 & 51.9 & 37.2 & 49.4 & -6.6 & & $<0.001$ \\
\hline MVPA (\%) & 4.0 & 89.3 & 3.3 & 91.6 & -0.7 & & \\
\hline
\end{tabular}

Mean = Arithmetic mean for non-compositional variables and compositional mean for time-use components expressed in percentages, Var $=$ Standard deviation for non-compositional variables and the percentage of total variance of log-ratios related to a given time-use component, $p=p$-value from the paired t-test for non-compositional variables and Hotelling test for movement behavior composition), BMI = body mass index, SB = time spent in sedentary behavior, LPA = time spent in light physical activity, MVPA = time spent in moderate-to-vigorous physical activity

${ }^{a}$ difference in movement composition variables was expresses as follow-up \% minus baseline \%

association between baseline adiposity and 7-year changes in movement-behavior composition.

Longitudinal changes in adiposity and movementbehavior composition found in our study concur with previous findings of age-related increase in adiposity [5, 6] and time spent in SB [33-35] and age-related decrease PA [36-38]. Furthermore, over the 7-year study period, the elderly women in our sample became more sedentary and less physically active. The increase of SB at the expense of MVPA is broadly considered to increase the risk of adverse health outcomes $[39,40]$.

The results of this study did not provide clear evidence of the association between baseline adiposity and subsequent changes in movement-behavior composition.

Table 2 Associations between adiposity and 7-year changes in movement-behavior composition: results of a least-squares regression analysis

\begin{tabular}{|c|c|c|c|c|c|c|c|c|c|c|c|c|}
\hline & \multicolumn{4}{|l|}{ Model 1} & \multicolumn{4}{|l|}{ Model 2} & \multicolumn{4}{|l|}{ Model 3} \\
\hline & \multicolumn{2}{|c|}{$\begin{array}{l}\text { (SB/LPA + SB/ } \\
\text { MVPA) difference }\end{array}$} & \multicolumn{2}{|c|}{$\begin{array}{l}\text { (LPA/MVPA) } \\
\text { difference }\end{array}$} & \multicolumn{2}{|c|}{$\begin{array}{l}\text { (LPA/SB + LPA/ } \\
\text { MVPA) difference }\end{array}$} & \multirow{2}{*}{$\begin{array}{l}\text { (SB/MVPA) } \\
\text { difference } \\
\beta \\
(95 \% \mathrm{Cl})\end{array}$} & \multicolumn{4}{|c|}{$\begin{array}{l}\text { (MVPA/SB + } \\
\text { MVPA/LPA) difference }\end{array}$} & \multirow{2}{*}{$\begin{array}{l}\text { (SB/LPA) } \\
\text { difference } \\
p\end{array}$} \\
\hline & $\begin{array}{l}\beta \\
(95 \% \mathrm{Cl})\end{array}$ & $p$ & $\begin{array}{l}\beta \\
(95 \% \mathrm{Cl})\end{array}$ & $p$ & $\begin{array}{l}\beta \\
(95 \% \mathrm{Cl})\end{array}$ & $p$ & & $\bar{p}$ & $\begin{array}{l}\beta \\
(95 \% \mathrm{Cl})\end{array}$ & $p$ & $\begin{array}{l}\beta \\
(95 \% \mathrm{Cl})\end{array}$ & \\
\hline $\begin{array}{l}\text { Baseline BMI (kg/ } \\
\left.\mathrm{m}^{2}\right)\end{array}$ & $\begin{array}{l}0.002 \\
(-0.014 \\
0.018)\end{array}$ & 0.848 & $\begin{array}{l}0.009 \\
(-0.013 \\
0.031)\end{array}$ & 0.434 & $\begin{array}{l}0.010 \\
(-0.013 \\
0.033)\end{array}$ & 0.40 & $\begin{array}{l}0.009 \\
(-0.011 \\
0.029)\end{array}$ & 0.382 & $\begin{array}{l}-0.011 \\
(-0.033 \\
0.012)\end{array}$ & 0.342 & $\begin{array}{l}-0.004 \\
(-0.017 \\
0.010)\end{array}$ & 0.604 \\
\hline $\begin{array}{l}\text { Change in BMl } \\
\left(\mathrm{kg} / \mathrm{m}^{2}\right)\end{array}$ & $\begin{array}{l}0.042 \\
(0.011 \\
0.073)\end{array}$ & 0.009 & $\begin{array}{l}0.045 \\
(-0.008 \\
0.098)\end{array}$ & 0.095 & $\begin{array}{l}0.02 \\
(-0.036 \\
0.075)\end{array}$ & 0.487 & $\begin{array}{l}0.057 \\
(0.009,0.105)\end{array}$ & 0.021 & $\begin{array}{l}-0.059 \\
(-0.115,- \\
0.004)\end{array}$ & 0.037 & $\begin{array}{l}0.026 \\
(-0.006 \\
0.058)\end{array}$ & 0.115 \\
\hline Baseline FM\% & $\begin{array}{l}0.007 \\
(-0.003 \\
0.016)\end{array}$ & 0.150 & $\begin{array}{l}0.013 \\
(-0.001 \\
0.027)\end{array}$ & 0.072 & $\begin{array}{l}0.009 \\
(-0.002 \\
0.019)\end{array}$ & 0.126 & $\begin{array}{l}0.013 \\
(-0.001 \\
0.026)\end{array}$ & 0.072 & $\begin{array}{l}-0.015 \\
(-0.031 \\
0.000)\end{array}$ & 0.056 & $\begin{array}{l}0.001 \\
(-0.005 \\
0.008)\end{array}$ & 0.679 \\
\hline Change in FM\% & $\begin{array}{l}0.019 \\
(0.008 \\
0.036)\end{array}$ & 0.031 & $\begin{array}{l}0.020 \\
(-0.004 \\
0.045)\end{array}$ & 0.108 & $\begin{array}{l}0.009 \\
(-0.010 \\
0.029)\end{array}$ & 0.351 & $\begin{array}{l}0.025 \\
(-0.001 \\
0.052)\end{array}$ & 0.057 & $\begin{array}{l}-0.027 \\
(-0.055 \\
0.001)\end{array}$ & 0.062 & $\begin{array}{l}0.011 \\
(-0.001 \\
0.022)\end{array}$ & 0.082 \\
\hline
\end{tabular}

Note: All models were adjusted for age, country, education, follow-up duration, baseline and follow-up wear time, baseline movement-behavior composition, residence change, baseline employment status, change in employment status, baseline health status and change in health status, baseline marital status and follow-up marital status. Baseline adiposity models were additionally adjusted for change in adiposity, while change in adiposity models were additionally adjusted for baseline adiposity. The outcome variable in each model represents the difference between the respective pivot coordinates at follow-up and baseline. For ease of interpretation, the first pivot coordinate has been expressed as the sum of individual log-ratios

A positive beta suggests that an increase in the respective explanatory variable is associated with an expected increase in the time spent in the movement behavior that is in the numerator of the pivot coordinate at the expense of the movement behavior(s) that is (are) in the denominator of the pivot coordinate. A negative beta suggests that an increase in the respective explanatory variable is associated with an expected decrease in the time spent in the movement behavior that is in the numerator of the pivot coordinate in favor of the movement behavior(s) that is (are) in the denominator of the pivot coordinate $\beta=$ unstandardised regression coefficient, expected change in the pivot coordinate associated with a unit increase in the explanatory variable, $C I$ confidence interval, SB sedentary behavior, LPA light physical activity, MVPA moderate-to-vigorous physical activity, BMI body mass index, FM\% fat mass percentage, Change change baseline to follow-up 
Some previous prospective studies suggest obesity might be a risk factor for decrease in PA [8] or may lead to increase in SB [9]. However, these studies included mainly middle-aged populations and did not consider the movement behaviors as compositional data. Given the lack of previous evidence for prospective associations between adiposity and subsequent changes in movementbehavior composition, it is not possible to make direct comparisons of our results with findings from previous studies. Some of the non-significant associations between baseline adiposity and subsequent changes in movement behaviors found in our study sample point in the same direction as the associations found in previous, non-CoDA based studies $[8,9,41]$. For example, in our sample, higher baseline FM\% was associated with an increase of SB at the expense of MVPA and with a decrease of MVPA in favor of SB and LPA. It is possible that these associations were not significant, because the sample in our study was smaller than in the two previous studies [9, 41]. A post hoc analysis of statistical power revealed that our sample size was large enough to ensure $>0.99$ probability of obtaining a significant beta coefficient, if the true effect size in the population is at least medium $\left(f^{2} \geq 0.15\right)$ [42]. The probability of obtaining a significant beta coefficient in case the true effect size in the population is small $\left(f^{2} \geq 0.02\right)$ was 0.46 , which is relatively low. However, Pulsford and colleagues [41] did not find a prospective association between baseline adiposity and total sitting time either, despite the fact their study was conducted in a much larger sample. The lack of significant associations in our study and in the Pulsford et al. study [41] might therefore also be an indication of a very low or no prospective association between adiposity and movement behaviors. Given the inconsistencies in findings between studies, this should be further investigated.

Although there were no prospective associations, we found significant longitudinal change-to-change associations. Our findings suggested that 7-year increases in both BMI and FM\% were associated with a concurrent increase of SB at the expense of other movement behaviors. And conversely, longitudinal decrease in BMI was associated with a decrease of MVPA in favor of other movement behaviors. It is possible that the change in adiposity is more important in determining concurrent changes to movement behaviors than starting levels of adiposity. This may reflect older women's decreasing ability to participate in MVPA and increasing propensity for SB and LPA as their adiposity increases. However, given that these were change-tochange associations, we are unable to determine the direction of this association and more research is needed to confirm these assumptions.
The main strengths of this study are its longitudinal design, the use of CoDA, and the assessment of movement behaviors using accelerometers. Additionally, the carefully selected adjustments for confounding strengthen the findings of this study. This study was subject to several limitations. The sample cannot be considered as fully representative of the population of elderly women in the Czech Republic, Poland and the Slovak Republic. The findings should, therefore, be generalized with caution. Furthermore, we did not find significant differences in baseline movement behaviours between the participants included in the analysis and those who were lost to follow-up. However, the latter group had a significantly higher age (by on average 2.03 years), BMI (by on average $1.1 \mathrm{~kg} / \mathrm{m}^{2}$ ), and fat mass percentage (by on average $2.3 \%$ ) compared with those who remained in the study. This may also have reduced the generalisability of findings. There are also limitations related to the assessment of movement behaviors. We did not measure sleep duration, despite the fact that sleep has been found to be associated with adiposity [43] and is co-dependent with SB, LPA and MVPA. A potential limitation may stem from our choice of the threshold for non-wear time. The large amount of time that older adults spend in sedentary behaviours, increases the likelihood of misclassifying sedentary time as non-wear time [44]. Some authors have, therefore, suggested using longer thresholds for non-wear time for older adults [45]. Despite that, the 60min threshold that we used in the current paper remains the most commonly used threshold in epidemiological studies conducted in this age group [22]. Furthermore, the accelerometer cut-points used to determine the time spent in movement behaviors were validated in samples with somewhat different characteristics compared with our study sample. We also did not consider other characteristics movement behaviors such as bout length, timing and consistency, some of which have been associated with adiposity in older women [15]. Lastly, although the regression models were adjusted for illness or disability occurrence before baseline and during the 7-year follow-up, it may be that some aspects of illness and disability were not fully captured by this question. This may have led to residual confounding.

\section{Conclusion}

This longitudinal study with device-measured daily composition of movement behaviors did not support the assumption that baseline adiposity is associated with longitudinal changes in movement behaviors among elderly women. However, we found evidence for change-tochange associations, suggesting that a 7-year increase in adiposity is associated with a concurrent increase of SB at the expense of LPA and MVPA and with a concurrent decrease of MVPA in favor of LPA and SB. Public health interventions are needed to simultaneously prevent weight gain and promote physically active lifestyle in the population of elderly women. 


\section{Supplementary Information}

The online version contains supplementary material available at https://doi. org/10.1186/s12877-021-02148-3.

Additional file 1: Supplementary material: Formulas of multiple regression models.

\begin{abstract}
Acknowledgements
We are thankful to the research personnel at the Institute of Active lifestyle and Department of Natural Sciences in Kinanthropology for their help with the data collection in the Czech Republic. We are also thankful to Izabela Zając-Gawlak and Lenka Tlučáková for helping with the data collection in Poland and the Slovak Republic, respectively. We would also like to thank all the participants for their involvement in the study.
\end{abstract}

\section{Authors' contributions}

JP conceived the idea for this study, obtained funding for the study, contributed to acquisition, analysis and interpretation of data, contributed to drafting the manuscript and is guarantor for the study. NŠ analyzed data, contributed to the interpretation of data and critically revised the manuscript. ŽP helped conceptualize the study idea, contributed to data analyses by creating a directed acyclic graph, contributed to writing the manuscript and critically revised the manuscript. TO helped conceptualize the study idea, contributed to drafting the manuscript and critically revised the manuscript. DD contributed to the interpretation of results, contributed to writing the manuscript and critically revised the manuscript. $\mathrm{KH}$ helped to design statistical analyses, interpret the data, and critically revised the manuscript. SCH contributed to design of the study and critically revised the manuscript. All authors read and approved the final manuscript.

\section{Funding}

The study was supported by a research grant from the Czech Science Foundation No. 18-16423S. These funding sources had no role in the design of the study and did not have any role in collection, analysis, and interpretation of the data or in writing the manuscript.

\section{Availability of data and materials}

The datasets generated during and/or analyzed during the current study are available in the Figshare repository, https://doi.org/10.6084/m9.figshare. 13208000.v2

\section{Declarations}

\section{Ethics approval and consent to participate}

All participants were informed that their participation was voluntary and that they could withdraw from the study at any time. They provided their written informed consent before participating in baseline and follow-up measurements. All methods were carried out in accordance with relevant guidelines and regulations. The study was approved by the Institutional Research Ethics Committee, Faculty of Physical Culture, Palacký University Olomouc (Ref. No. 20/2017).

\section{Consent for publication}

Not applicable.

\section{Competing interests}

The authors declare that they have no competing interests.

\section{Author details}

${ }^{1}$ Faculty of Physical Culture, Palacký University Olomouc, Institute of Active Lifestyle, Tř. Míru 117, 77111 Olomouc, Czech Republic. ${ }^{2}$ Faculty of Science, Palacký University Olomouc, Olomouc, Czech Republic. ${ }^{3}$ Alliance for Research in Exercise, Nutrition and Activity (ARENA), University of South Australia, Adelaide, South Australia, Australia. ${ }^{4}$ School of Health and Life Science, Glasgow Caledonian University, Glasgow, UK. ${ }^{5}$ Institute for Health and Sport, Victoria University, Melbourne, Australia.
Received: 29 December 2020 Accepted: 10 March 2021

Published online: 23 March 2021

\section{References}

1. Zhu W, Cheng Z, Howard VJ, Judd SE, Blair SN, Sun Y, et al. Is adiposity associated with objectively measured physical activity and sedentary behaviors in older adults? BMC Geriatr. 2020;20(1):1-8.

2. de Rezende LFM, Rey-Lopez JP, VKR M, do Carmo Luiz O. Sedentary behavior and health outcomes among older adults: a systematic review. BMC Public Health. 2014;14:333.

3. Svozilová Z, Pelclová J, Pechová J, Přidalová M, Zając-Gawlak I, Tlučáková L, et al. Associations between adiposity and physical activity and sedentary behaviour patterns in older women. Acta Gymnica. 2019:49(2):83-91. https://doi.org/10.5507/ag.2019.006

4. Wanner M, Richard A, Martin B, Faeh D, Rohrmann S. Associations between self-reported and objectively measured physical activity, sedentary behavior and overweight/obesity in NHANES 2003-2006. Int J Obes. 2017;41(1):18693. https://doi.org/10.1038/ijo.2016.168.

5. Hughes VA, Frontera WR, Roubenoff R, Evans WJ, Fiatarone Singh MA Longitudinal changes in body composition in older men and women: role of body weight change and physical activity. Am J Clin Nutr. 2002;76(2): 473-81. https://doi.org/10.1093/ajcn/76.2.473.

6. Raguso CA, Kyle U, Kossovsky MP, Roynette C, Paoloni-Giacobino A, Hans D, Genton L, Pichard C. A 3-year longitudinal study on body composition changes in the elderly: role of physical exercise. Clin Nutr. 2006;25(4):573-80 https://doi.org/10.1016/j.clnu.2005.10.013.

7. Tremblay MS, Aubert S, Barnes JD, Saunders TJ, Carson V, Latimer-Cheung

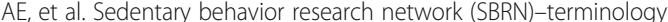
consensus project process and outcome. Int J Behav Nutr Phys Act. 2017; 14(1):1-17.

8. Tucker JM, Tucker LA, Lecheminant J, Bailey B. Obesity increases risk of declining physical activity over time in women: a prospective cohort study. Obesity. 2013;21(12):715-20.

9. Pedišić Ž, Grunseit A, Ding CJY, Banks E, Stamatakis E, et al. High sitting time or obesity: which came first? Bidirectional association in a longitudinal study of 31,787 Australian adults. Obesity. 2014;22(10):2126-30. https://doi.org/10.1 002/oby.20817.

10. Chastin SFM, Palarea-Albaladejo J, Dontje ML, Skelton DA. Combined effects of time spent in physical activity, sedentary behaviors and sleep on obesity and cardio-metabolic health markers: a novel compositional data analysis approach. PLoS One. 2015;10(10):e0139984. https://doi.org/10.1371/journal. pone.0139984

11. Pedišić Ž. Measurement issues and poor adjustments for physical activity and sleep undermine sedentary behaviour research - the focus should shift to the balance between sleep, sedentary behaviour. Standing and Activity Kinesiology. 2014;46(1):135-46.

12. Pedišić Ž, Dumuid D, Olds T. Integrating sleep, sedentary behaviour, and physical activity research in the emerging field of time-use epidemiology: definitions, concepts, statistical methods, theoretical framework, and future directions. Kinesiology. 2017:49(2):252-69.

13. Dumuid D, Stanford TE, Martin-Fernández JA, Pedišić Ž, Maher CA, Lewis LK, Hron K, Katzmarzyk PT, Chaput JP, Fogelholm M, Hu G, Lambert EV, Maia J, Sarmiento OL, Standage M, Barreira TV, Broyles ST, Tudor-Locke C, Tremblay MS, Olds T. Compositional data analysis for physical activity, sedentary time and sleep research. Stat Methods Med Res. 2018;27(12):3726-38. https://doi. org/10.1177/0962280217710835.

14. Gupta N, Mathiassen SE, Mateu-Figueras G, Heiden M, Hallman DM, Jørgensen MB, Holtermann A. A comparison of standard and compositional data analysis in studies addressing group differences in sedentary behavior and physical activity. Int J Behav Nutr Phys Act. 2018;15(1):1-12.

15. Gába A, Pelclová J, Štefelová N, Přidalová M, Zając-Gawlak I, Tlučáková L, Pechová J, Svozilová Z. Prospective study on sedentary behaviour patterns and changes in body composition parameters in older women: a compositional and isotemporal substitution analysis. Clin Nutr. 2020. https:// doi.org/10.1016/j.clnu.2020.10.020

16. Pelclová J, Štefelová N, Dumuid D, Pedišić Ž, Hron K, Gába A, Olds T, Pechová J, Zając-Gawlak I, Tlučáková L. Are longitudinal reallocations of time between movement behaviours associated with adiposity among elderly women? A compositional isotemporal substitution analysis. Int Obes. 2020;44(4):857-64. https://doi.org/10.1038/s41366-019-0514-x. 
17. Cuberek R, Pelclová J, Gába A, Pechová J, Svozilová Z, Přidalová M, et al. Adiposity and changes in movement-related behaviors in older adult women in the context of the built environment: a protocol for a prospective cohort study. BMC Public Health. 2019;19(1):1-7.

18. Gába A, Kapuš O, Cuberek R, Botek M. Comparison of multi- and singlefrequency bioelectrical impedance analysis with dual-energy $X$-ray absorptiometry for assessment of body composition in post-menopausal women: effects of body mass index and accelerometer-determined physical activity. J Hum Nutr Diet. 2014;28(4):390-400. https://doi.org/10.1111/jhn.122 57.

19. Park KS, Lee DH, Lee J, Kim YJ, Jung KY, Kim KM, Kwak SH, Choi SH, Park KS, Jang HC, Lim S. Comparison between two methods of bioelectrical impedance analyses for accuracy in measuring abdominal visceral fat area. J Diabetes Complicat. 2016;30(2):343-9. https://doi.org/10.1016/j.jdiacomp.201 5.10.014.

20. WHO Expert Committee. Physical Status: the use and interpretation of anthropometry. WHOTechnical Report Series no. 854. Geneva: WHO; 1995.

21. Gallagher D, Heymsfield SB, Heo M, Jebb SA, Murgatroyd PR, Sakamoto Y. Healthy percentage body fat ranges: an approach for developing guidelines based on body mass index. Am J Clin Nutr. 2000;72(3):694-701. https://doi. org/10.1093/ajen/72.3.694.

22. Gorman E, Hanson HM, Yang PH, Khan KM, Liu-Ambrose T, Ashe MC. Accelerometry analysis of physical activity and sedentary behavior in older adults: a systematic review and data analysis. Eur Rev Aging Phys Act. 2014; 11(1):35-49. https://doi.org/10.1007/s11556-013-0132-x.

23. Freedson PS, Melanson E, Sirard J. Calibration of the computer science and applications. Inc accelerometer Med Sci Sports Exerc. 1998;30(5):777-81. https://doi.org/10.1097/00005768-199805000-00021.

24. R Core Team. R Foundation for Statistical computing, Vienna, Austria; 2020 https://www.r-project.org/

25. van den Boogaart GK, Tolosana R, Bren M. Package 'compositions'. 2015. https://cran.r-project.org/web/packages/compositions/compositions.pdf

26. Pawlowsky-Glahn V, Egozcue JJ, Tolosana-Delgado R. Modeling and analysis of compositional data. London: Wiley; 2015.

27. Dumuid D, Pedišić Ž, Palarea-Albaladejo J, Martín-Fernández JA, Hron K, Olds T. Compositional data analysis in time-use epidemiology: what, why, how. Int J Environ Res Public Health. 2020;17(7):2220. https://doi.org/10.33 90/ijerph17072220.

28. Filzmoser P, Hron K, Templ M. Applied compositional data analysis. With worked examples in R. Cham: Springer International Publishing; 2018. https://doi.org/10.1007/978-3-319-96422-5.

29. Chastin SFM, Buck C, Freiberger E, Murphy M, Brug J, Cardon G, et al. Systematic literature review of determinants of sedentary behaviour in older adults: a DEDIPAC study. Int J Behav Nutr Phys Act. 2015;12(1):1-12.

30. UKK Institute for Health Promotion Research. Aikuisten liikkumisen suositus [Movement recommendations for adults]. https://ukkinstituutti.fi/ liikkuminen/liikkumisen-suositukset/liikkumisen-suositus-yli-65-vuotiaille. Accessed 11 Nov 2020.

31. Canadian Society for Exercise Physiology. Canadian 24-Hour Movement Guidelines for Adults ages 65 years and older: An Integration of Physical Activity, Sedentany Behaviour, and Sleep https:/csepguidelines.ca/adults-65. Accessed 9 Nov 2020.

32. Jurakić D, Pedišić Ž. Croatian 24-hour guidelines for physical activity, sedentary behaviour, and sleep: a proposal based on a systematic review of literature. Medicus. 2019;28(2):143-53.

33. Harvey JA, Chastin SFM, Skelton DA. How sedentary are older people? A systematic review of the amount of sedentary behavior. J Aging Phys Act. 2015;23(3):471-87. https://doi.org/10.1123/japa.2014-0164.

34. Clark BK, Sugiyama T, Healy GN, Salmon J, Dunstan DW, Shaw JE, Zimmet PZ, Owen N. Socio-demographic correlates of prolonged television viewing time in australian men and women: the AusDiab study. J Phys Act Health. 2010;7(5):595-601. https://doi.org/10.1123/jpah.7.5.595.

35. Martin KR, Koster A, Murphy RA, Van Domelen DR, Hung MY, Brychta RJ, et al. Changes in daily activity patterns with age in U.S. men and women: national health and nutrition examination survey 2003-04 and 2005-06. J Am Geriatr Soc. 2014;62(7):1263-71. https://doi.org/10.1111/jgs.12893.

36. Doherty A, Jackson D, Hammerla N, Plötz T, Olivier P, Granat MH, et al. Large scale population assessment of physical activity using wrist worn accelerometers: the UK biobank study. PLoS One. 2017;12(2):1-14

37. Berkemeyer K, Wijndaele K, White T, Cooper AJM, Luben R, Westgate K, et al. The descriptive epidemiology of accelerometer-measured physical activity in older adults. Sci Rep. 2016;7(5):1-10.
38. Troiano R, Berrigan D, Dodd K, Mâsse L, Tilert T, Mcdowell M. Physical activity in the United States measured by accelerometer. Med Sci Sport Exer. 2008;40(1):181-8. https://doi.org/10.1249/mss.0b013e31815a51b3.

39. Grgic J, Dumuid D, Bengoechea EG, Shrestha N, Bauman A, Olds T, et al. Health outcomes associated with reallocations of time between sleep, sedentary behaviour, and physical activity: a systematic scoping review of isotemporal substitution studies. Int J Behav Nutr Phys Act. 2018;15(1):1-68.

40. Janssen I, Clarke AE, Carson V, Chaput J-P, Giangregorio LM, Kho ME, et al. A systematic review of compositional data analysis studies examining associations between sleep, sedentary behaviour, and physical activity with health outcomes in adults. Appl Physiol Nutr Metab. 2020;45(10 Suppl 2): 248-57.

41. Pulsford RM, Stamatakis E, Britton AR, Brunner EJ, Hillsdon MM. Sitting behavior and obesity: evidence from the Whitehall II study. Am J Prev Med. 2013:44(2):132-8. https://doi.org/10.1016/j.amepre.2012.10.009.

42. Cohen J. A power primer. Psychol Bull. 1992;112(1):155-9. https://doi.org/1 0.1037/0033-2909.112.1.155.

43. Garfield V, Llewellyn CH, Steptoe A, Kumari M. Investigating the bidirectional associations of adiposity with sleep duration in older adults: the English longitudinal study of ageing (ELSA). Sci Rep. 2017;7:1-8.

44. Winkler EA, Gardiner PA, Clark BK, Matthews CE, Owen N, Healy GN. (2012). Identifying sedentary time using automated estimates of accelerometer wear time. Br J Sports Med. 2012;46(6):436-42. https://doi.org/10.1136/ bjsm.2010.079699.

45. Chudyk AM, MCAllister MM, Cheung HK, McKay HA, Ashe MC. Are we missing the sitting? Agreement between accelerometer non-wear time validation methods used with older adults' data. Cogent medicine. 2017; 4(1):1313505. https://doi.org/10.1080/2331205X.2017.1313505.

\section{Publisher's Note}

Springer Nature remains neutral with regard to jurisdictional claims in published maps and institutional affiliations.

Ready to submit your research? Choose BMC and benefit from:

- fast, convenient online submission

- thorough peer review by experienced researchers in your field

- rapid publication on acceptance

- support for research data, including large and complex data types

- gold Open Access which fosters wider collaboration and increased citations

- maximum visibility for your research: over $100 \mathrm{M}$ website views per year

At BMC, research is always in progress.

Learn more biomedcentral.com/submissions 